\title{
Optimal ways to improve the greening of the production sector
}

\author{
Svetlana Ovchinnikova $a^{1, *}$, Aleksandr Borovkov $^{2}$, Elena Schneider $^{2}$, and Andrey \\ Kalinichenko ${ }^{3}$ \\ ${ }^{1}$ I. T. Trubilin Kuban State Agrarian University, 350012, 13 Kalinina str., Krasnodar, Russia \\ ${ }^{2}$ Nevinnomyssk State Humanitarian and Technical Institute, 357108, 17 Mira boulevard, \\ Nevinnomyssk, Russia \\ ${ }^{3}$ North-Caucasus Federal University, 355017, Pushkin Str., 1, Stavropol, Russia
}

\begin{abstract}
The paper discusses a system of criteria that make it possible to assess the level of environmental safety of an enterprise. The model of the "nature-population-production" system and the very interaction of the system are presented. Environmental problems, problems of ecology of production, and consumption of natural resources lead to an increase in the rate of growth of production, which, in turn, leads to an increase in demand for resources, and as a consequence, to their irrational use, and then to massive emissions into the environment as waste. In order to improve the environmental situation in the country, some areas for improving the greening of the production sector are presented, which increase the efficiency of consumption and use of natural resources, while reducing environmental pollution by emissions, effluents, and waste. The main indicators that determine the level of environmental management are presented - indicators of resource intensity, an indicator of the degree of restoration of natural resources, and indicators of saving primary natural resources. All three indicators are part of the specific consumption of natural resources and can be used at the enterprise to control the consumption of natural resources, as well as in order to minimize waste through the use of secondary resources and low-waste technologies. The established ways of improving the greening of the production sector are able to improve the ecological situation in the regions of the country and establish the relationship between man, nature and the production sector.
\end{abstract}

\section{Introduction}

Human economic activity, manufacture, production and use of products and services occurs within the framework of a close exchange of materials and energy with the environment [14]. Entering into a relationship with the natural environment, an industrial enterprise forms with it a kind of dynamic ecological and economic system, the main property of which is the balance and proportionality of its natural and production subsystems [5-7].

\footnotetext{
* Corresponding author: Svetlana.swetlana-ov@yandex.ru
} 
The incomplete 2020 broke the previous record for the number of recorded cases of high and extremely high air pollution ahead of schedule, becoming the "dirtiest" year in at least 16 years [8-9]. After the spring quarantine, the recorded pollution began to grow rapidly. The number of toxic emissions into the atmosphere for nine months from the beginning of the year exceeded the last maximum ten years ago by a third, and compared to 2019 , the amount of pollution has jumped three times. The most unfavorable situation has developed in the Samara region, Buryatia, the Orenburg region, the Trans-Baikal and Krasnoyarsk regions.

Back in January-February 2020, the amount of air pollution increased by one and a half times compared to the same period last year. But since the beginning of spring, during which there was a period of non-working days and quarantine due to the coronavirus pandemic, and until the end of June, only two cases of high air pollution were recorded. In

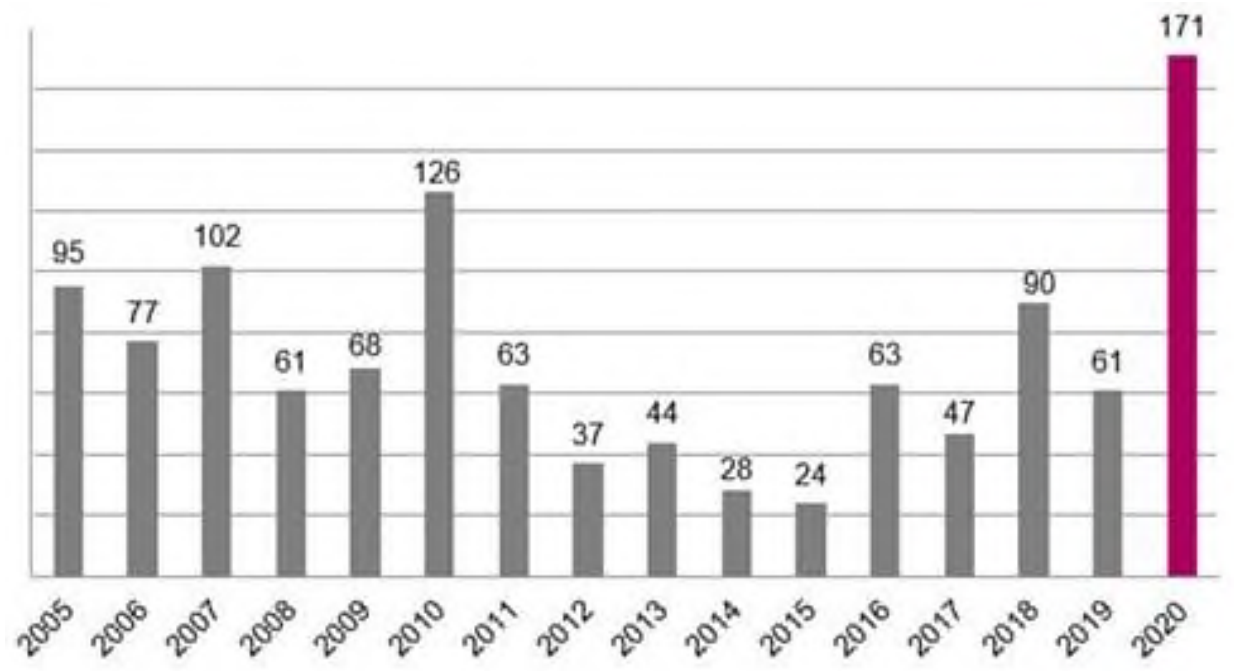

July, when the regions had already lifted the most stringent quarantine restrictions, the amount of air pollution began to grow sharply (Fig. 1).

Fig. 1. Graph of air pollution by years.

High and extremely high pollution can cause significant harm to the environment and human health

The aim of the study is to determine the best ways to improve the greening of the production sector. Since the increasing interconnection of production, technological and biological processes reveals the fact that the economy and ecology, man and nature are not antipodes, but elements of a single ecological and economic system, which requires the integration of their laws and methods into a single methodology for managing this system for its sustainable development [10].

\section{Methods and materials}

The study presents a model of interaction of the "nature-population-production" system. The fundamental element of this model (Fig. 2) is a person, for the sake of whom production exists.

The block "nature" is defined, which is characterized by:

- the level of soil erosion;

- the number of trees cut down; 
- the amount of fish caught;

- the amount of water consumed;

- indicators of carbon dioxide emissions;

- assimilation abilities, etc.

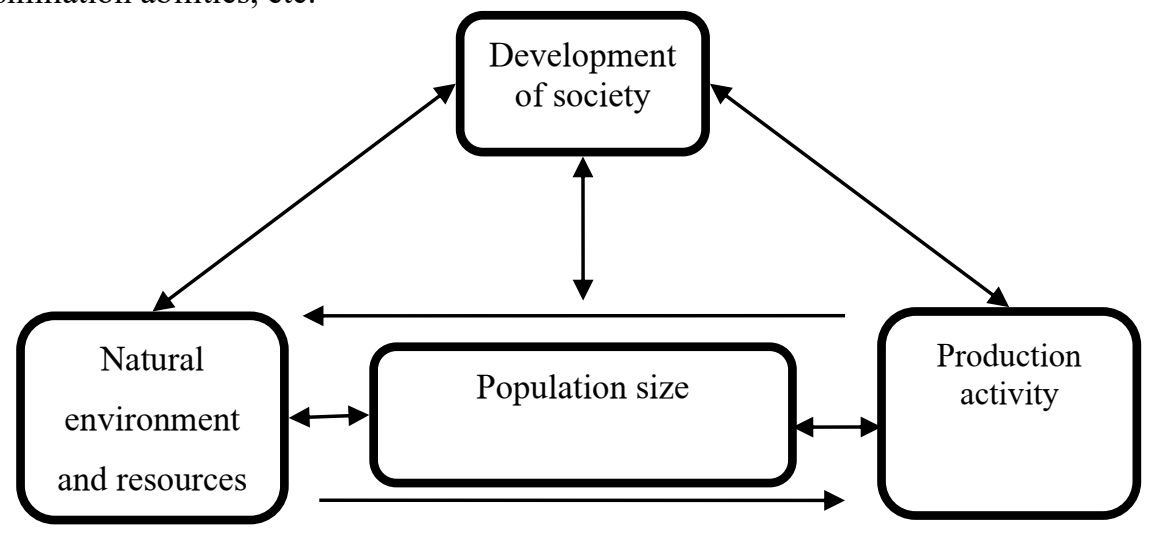

Fig. 2. Model of relationships in the "nature-population-production" system.

To a certain extent, the sustainability of the ecological block depends on production and population. Production depends on the development of economic activities, the economy within a specific social system, and the quality of life of the population. Economy is defined as the process of the relationship between people and nature. Production has an ambiguous effect on the overall development, since people living in urbanized areas assess the importance of production in the development system in two ways: as a source of material wealth and comfort in life and as a source of environmental degradation, stress, psychological fatigue, etc.

The interaction and influence of the elements of the model are inevitable, they are integral parts of socio-ecological and economic development.

Having noted and presented the interaction of all components of the modern model "nature - population - production", the main negative consequences of this interaction are highlighted:

- depletion of natural resources as a result of their uneven use in the production environment;

- environmental pollution as a result of human economic activity;

- decrease in ecological culture, etc.

\section{Results}

Nowadays, the economy must move to greening the production sector in order to improve the environmental situation in the country. Some ways to improve greening are shown in Fig. 3.

Improving the greening of the production sector involves the development of several areas:

- the greening of production processes is a steady and consistent introduction of technical, technological, organizational measures that increase the efficiency of consumption and use of natural resources, while reducing environmental pollution by emissions, effluents, and waste.

At the stages of preparing a feasibility study and developing a project for the reconstruction of an enterprise, an environmental impact assessment should be carried out, which includes the determination of the nature and degree of potential types of impact of 
production activities on the natural environment and the associated environmental, economic and social consequences.

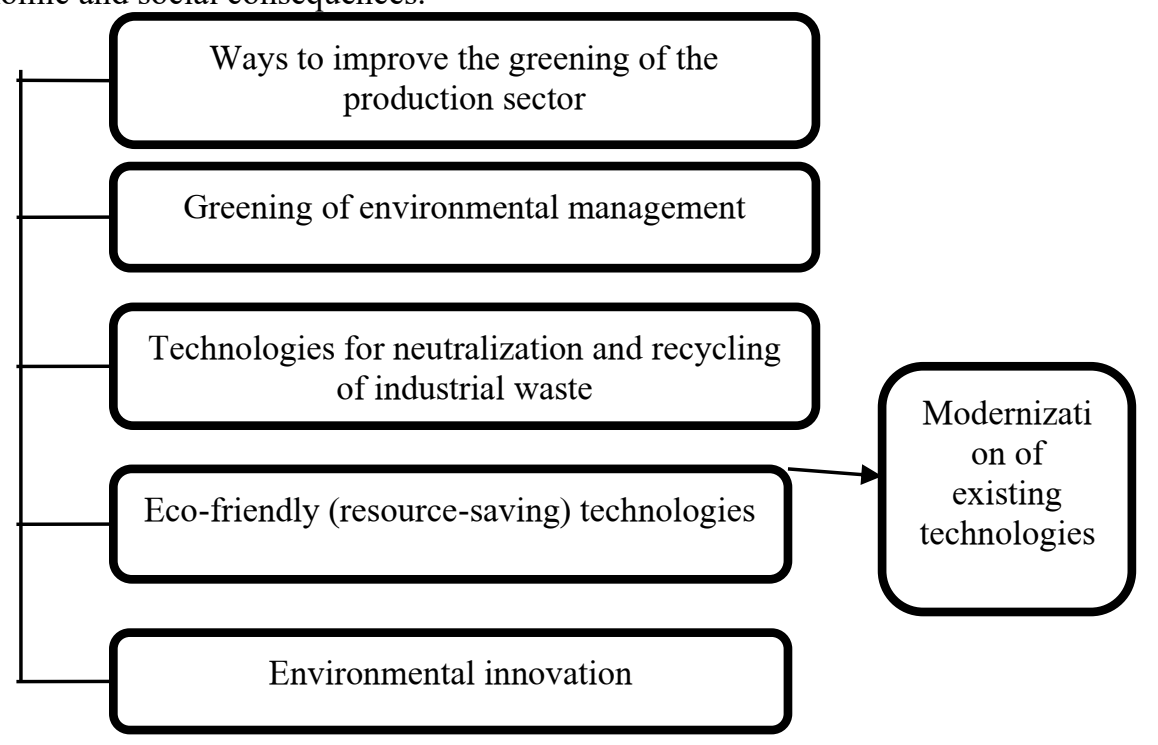

Fig. 3. Directions for improving the greening of the production sector.

The main indicators that determine the level of greening of environmental management:

1. The indicator of resource intensity, which is calculated by the formula:

$$
R n r=B p / P
$$

where Rnr - specific consumption of this type of natural resource per unit of finished product, is of a normative nature for most types of finished products; $\mathrm{Bp}$ - consumption of this type of resources for production; $\mathrm{P}$ - gross output

2. Indicator of the degree of restoration (reproduction) of natural resources that have changed due to anthropogenic impact:

$$
\mathrm{Cr}=\mathrm{Pr} / \mathrm{Pa}
$$

where $\operatorname{Pr}$ - the number of resources recovered; $\mathrm{Pa}$ - the total number of natural resources affected.

3. Indicator of saving primary natural resources based on the use of technologies:

$$
P s=P 1-P 2
$$

where P1 - the amount of resources consumed with the basic technology and the basic level of use of secondary resources; P2 - the volume of resource consumption when using new technology and additional involvement of secondary resources.

All three indicators belong to the category of specific consumption of natural resources (resource intensity) and can be used at the enterprise as a control over the consumption (use) of natural resources, as well as in order to minimize waste by using secondary resources and low-waste technologies. The indicators characterizing the organization of environmental management include indicators of waste intensity of production and environmental criteria.

The basis of the initial data in the calculation of these indicators is the project technical, regulatory, and financial documentation of enterprises. 
As for the volumes of waste generation of all hazard classes, they are constantly growing, both in the country as a whole and in individual regions. The average rate of waste recycling and disposal is no more than $60 \%$, which leads to a deterioration in the economic conditions in Russia. The classification of technologies for the neutralization and disposal of hazardous toxic waste is shown in Fig. 4.



Fig. 4. Classification of technologies for neutralization and disposal of hazardous production and consumption waste.

According to the classification shown in Figure 4, enterprises can use existing technologies to reduce waste and emissions into the environment. Low-waste and zerowaste technologies and closed cycles are one of the most radical measures to protect the environment from pollution.

Using the presented indicators, it is possible to use the method for economic improvement of chemical processes and specific waste generation. Greening of environmental management will allow the rational use of natural resources, minimization of waste generation, use of secondary resources and low-waste technologies in the production sector.

There are the main areas for the development of low-waste (waste-free) technology:

- creation of drainless technological systems for various purposes on the basis of existing and promising methods of purification and re-sequential use of effluents treated according to the norms;

- development and implementation of industrial waste processing systems, which are considered in this case as secondary material resources;

- development of technological processes for obtaining traditional types of products by fundamentally new methods, in which the maximum possible transfer of matter and energy to finished products is achieved;

- development and creation of territorial-industrial complexes with the most complete closed structure of material flows and production wastes inside them.

Waste-free technology acts as an ecological strategy for industrial production, including a set of measures to ensure the minimum loss of natural resources with maximum economic efficiency. Waste-free technology is the ideal system that every real technological cycle should strive for, and the larger this approximation, the smaller the environmentally hazardous footprint. 
Creation of favorable conditions for the introduction of innovations is one of the priority tasks of environmental policy. The options for the greening of the production sector with the participation of innovations include:

- transition to the manufacture of environmentally friendly goods, for example, food. In this case, the goods known to consumers acquire a new quality;

- change in production technology in order to reduce emissions and discharges of pollutants, reduce the consumption of materials, release environmentally friendly goods, i.e. the introduction of new technologies;

- reducing the consumption of natural raw materials or replacing the traditional source of raw materials. Green innovation differentiates itself from other innovations by producing additional externalities.

In the course of introducing environmental innovation in a competitive market, externalities "internationalize", the problem of additional externalities disappears, and environmental innovations can be considered ordinary innovations. Another feature of environmental innovations is the regulatory role of the state, whose task is to create conditions for the priority implementation of precisely environmentally oriented innovations. Thus, without public support and a change in people's mentality, it is almost impossible to implement green innovations.

\section{Discussion}

The choice of the most suitable technology for neutralizing the generated waste is not easy, because, first of all, the problem of increasing the level of environmental safety during the disposal and neutralization of highly hazardous waste generated in large cities arises. Second, the adaptation and choice of technology for a specific region or territory depends on the morphological and quantitative composition of the waste generated. The main methods of waste disposal are: mechanical, thermal, physicochemical and biological. A separate group should be allocated to the deposition of waste in specially designated disposal sites, which is used instead of or after waste processing.

\section{Conclusions}

Thus, with the achievement of optimal ways to improve the greening of production, it is possible to achieve the preservation of the biosphere, increase its adaptive and assimilating abilities based on ensuring biosphere compatibility and turning it into a control link to maintain the integrity of the biosphere.

In this sense, the greening of production will appear as a fundamental area of activities aimed at optimizing and harmonizing relations between society and nature, the transformation of the biosphere into the noosphere.

\section{References}

1. S. Ovchinnikova, M. Kalinichenko, N. Markina, E. Schneider, Energy modernization of housing stock, E3S W. of Conf. 157, 06028 (2020) https://doi.org/10.1051/e3sconf/202015706028

2. M.Y. Kalinichenko, N.I. Stojanov, D.V. Abornev, S.V. Ovchinnikova, Optimization of the regeneration of the sodium-cation ion-exchange filter, IOP Conf. Ser.: Mater. Sc. and Engin. 905(1), 012034 (2020) doi:10.1088/1757-899X/905/1/012034 
3. E. Tsoraeva, S. Mezhyan, M. Kataeva, L. Hugaeva, T. Rogova, GIS technologies used in zoning agricultural land for optimizing regional land use, E3S W. of Conf. 224, 03001 (2020) https://doi.org/10.1051/e3sconf/202022403001

4. E. Tsoraeva, A. Bekmurzov, S. Kozyrev, A. Khoziev, A. Kozyrev, Environmental issues of agriculture as a consequence of the intensification of the development of agricultural industry, E3S W. of Conf. 215, 02003 (2020) https://doi.org/10.1051/e3sconf/202021502003

5. G.V. Degtyarev, N.A. Bakhtamyan, The water structures operability analysis, taking into account damage and certain negative factors, IOP Conf. S.: Mat. Sci. and Eng. 913(2), 022053 (2020) https://doi:10.1088/1757-899X/913/2/022053

6. P. S. Pravin, Sh. Misra, Sh. Bhartiya, R. D.Gudi, Advanced control of a reformer based fuel cell system coupled with multiple, uncertain renewable energy sources and an energy storage system, IFAC-P. O. $\quad$ L. $53 \quad$ (1), 374-379 (2020) http://doi.org/10.1016/j.ifacol.2020.06.063

7. D.Kolcava, T. Bernauer, Greening the Economy through Voluntary Private Sector Initiatives or Government Regulation? A Public Opinion Perspective, Envir.Scien. \& Pol. 115, 61-70 (2021) https://doi.org/10.1016/j.envsci.2020.09.013

8. E. K. Sadanandan Nambiar, Strengthening Vietnam's forestry sectors and rural development: Higher productivity, value, and access to fairer markets are needed to support small forest growers, Trees, Forests and People 3, 100052 (2021) https://doi.org/10.1016/j.tfp.2020.100052

9. D. Fernándeza, C. Pozo, R. Folgado, G. Guillén-Gosálbez, L. Jiménez, Multiperiod model for the optimal production planning in the industrial gases sector, Appl. En. 206, 667-682 (2017)

10. S. Ovchinnikova, A. Sekisov, I. Shinkareva, E. Schneider, E. Tamoshkina, Implementation of investment and construction projects as part of the interior image formation, IOP Conf. S.: Mat. Sc. and Eng. 953(1), 0120822020 https://doi.org/10.1088/1757-899X/953/1/012082 